\title{
Erratum: The genomics of ecological vicariance in threespine stickleback fish
}

Marius Roesti, Benjamin Kueng, Dario Moser \& Daniel Berner

Nature Communications 6:8767 doi: 10.1038/ncomms9767 (2015); Published 10 Nov 2015; Updated 15 Dec 2015

The recombination rate around the chromosomal inversion in Fig. $6 \mathrm{f}$ of this Article was inadvertently omitted during the production process. The correct version of Fig. $6 \mathrm{f}$ appears below. 

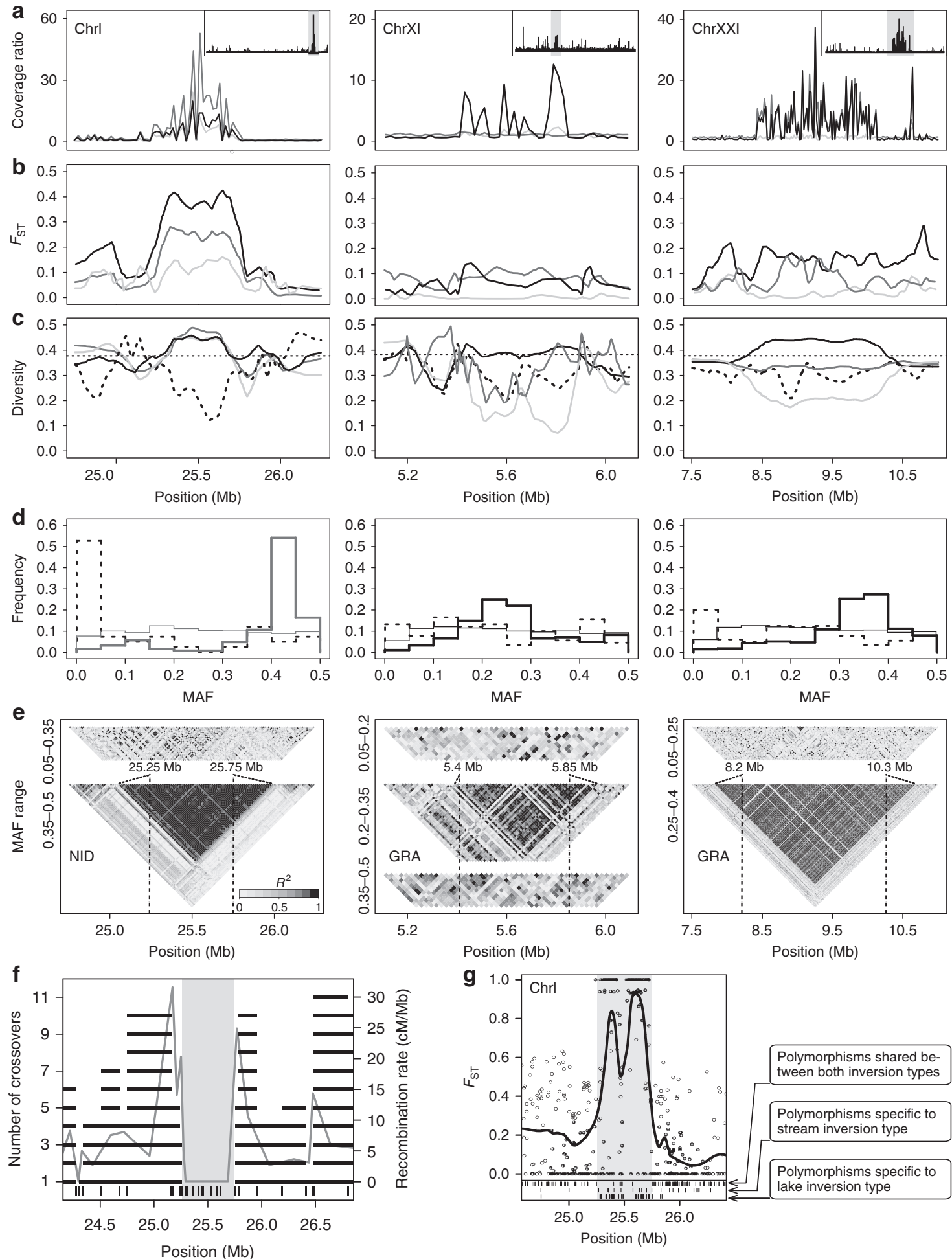

Figure 6.

This work is licensed under a Creative Commons Attribution 4.0 International License. The images or other third party material in this article are included in the article's Creative Commons license, unless indicated otherwise in the credit line; if the material is not included under the Creative Commons license, users will need to obtain permission from the license holder to reproduce the material. To view a copy of this license, visit http://creativecommons.org/licenses/by/4.0/ 